\title{
Evaluation of olfactory bulbus volume and olfactory sulcus depth development with 3 Tesla magnetic resonance imaging in childhood
}

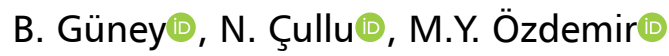 \\ Department of Radiology, Muğla Sıtkı Koçman University Medical Faculty, Muğla, Turkey
}

[Received: 15 December 2020; Accepted: 1 February 2021; Early publication date: 1 March 2021]

Background: This study aimed to reveal the change in olfactory bulbus volume $(O B V)$ and olfactory sulcus depth (OSD) in healthy Turkish paediatric individuals between 1 month and 18 years of age with 3 Tesla magnetic resonance imaging (MRI), taking into account different age groups and gender factors.

Materials and methods: In this retrospective study, 190 paediatric individuals who underwent cranial MRI were evaluated. Healthy paediatric cases were divided into four groups as infantile period (first 24 months when cerebral myelinisation was completed), early childhood (2-6 years), childhood (6-12 years) and adolescence (12-18 years). OBV and OSD measurements were performed on coronal T2-weighted brain MRI by 3 Tesla magnetic resonance scan. The mean, right and left OBVs and OSDs were used for evaluation.

Results: The mean age was $9.9 \pm 7.5$ months for the infantile period, $4.5 \pm 1.3$ years for early childhood, $9.3 \pm 1.7$ years for childhood and $15.2 \pm 1.7$ years for adolescence. Mean, right and left OBV was found to be slightly larger in male children than in female children ( $p=0.015, p=0.033$ and $p=0.010$, respectively). There was no statistical difference between the genders for mean, right and left OSD ( $p=0.559, p=0.536$ and $p=0.598$, respectively). Among the age groups, the values of the $3^{\text {rd }}$ and $4^{\text {th }}$ groups in terms of mean, right and left OBV were higher than in the other two groups $(p<0.001)$. In terms of OSD, mean, right and left values were higher in group 2, 3 and 4 than in group $1(p<0.001)$. Conclusions: These data differ by paediatric age group and gender for the development of OBV and OSD. Normal values for the paediatric age group and gender should be calculated to detect olfactory dysfunction. (Folia Morphol 2022; 81, 2: 307-313)

Key words: paediatric age, bulbus olfactorius, olfactory sulci, 3 Tesla magnetic resonance

\section{INTRODUCTION}

The sense of smell is one of the five senses that have an important function in human life, and the olfactory bulb (OB) is considered to be the most im- portant transmission station in processing the sense of smell. Anatomical structures of the sense of smell begin to develop early in the human foetus. There are studies and anatomical atlases on the development

Address for correspondence: Dr. B. Güney, Assistant Professor, Muğla Sıtkı Koçman University Medical Faculty, Department of Radiology, tel: +90 533 4911152, fax: +90252 2111345, e-mail: bunyaminguney@mu.edu.tr

This article is available in open access under Creative Common Attribution-Non-Commercial-No Derivatives 4.0 International (CC BY-NC-ND 4.0) license, allowing to download articles and share them with others as long as they credit the authors and the publisher, but without permission to change them in any way or use them commercially. 
and anatomical change of the primordial olfactory bulbus, which was first observed anatomically in a 41-day (4.5 week) embryo in the foetal development period, from gestation to birth $[2,13,15,17]$. However, the number of studies on the anatomical development and change of the olfactory bulbus in the paediatric period is limited. In a study conducted by Schneider and Floemer [18] about the maturation of the olfactory bulbus in the postnatal period, they found that olfactory bulbus showed a similar maturation parallel to the maturation of the cerebral white matter until the end of the second year, when the myelinisation and maturation of the cerebral white matter was completed. In this study, it was found that the olfactory bulbs took the adult shape at the end of the postnatal 24 months [18]. The first study on the anatomical development and change of olfactory bulbus volume (OBV) in the paediatric age group was conducted by Hummel et al. [10]. A positive relationship was found between increased OBV and increased olfactory function in this study performed in children aged 1 to 17 years. It was found that both OBV and olfactory function increased with age.

Another parameter used in evaluating olfactory functions is the depth of the olfactory sulcus. Some diseases such as major depression, anxiety disorder, Behçet's disease, Parkinson's and Alzheimer's disease have been shown to reduce the depth of the olfactory sulcus and cause a decrease in the sense of smell $[1,5,11]$. There are limited studies on the change of OBV and olfactory sulcus depth (OSD) with age in paediatric cases [16]. OBV and OSD are known to vary with age $[4,10]$. The age-related change and normal values of both OBV and OSD in healthy paediatric individuals are not clearly known.

This study aimed to reveal the change of OBV and OSD over time in healthy Turkish paediatric individuals between 1 month and 18 years of age with 3 Tesla magnetic resonance imaging (MRI) taking into account different age groups and gender factors.

\section{MATERIALS AND METHODS}

After being approved by the Ethics Committee of our University, the research was started retrospectively in the Radiology Department. Only children with normal brain MRI were included in the study. Paediatric individuals with any brain abnormality (developmental anomaly, myelinisation disorder, maturation disorder, etc.) or disease were excluded from the study. While evaluating the patients, the patient files registered in the hospital information system were taken as basis. Those with a genetic disease in their family, those with suspected congenital neurometabolic disease, chronic diseases such as diabetes mellitus and hypertension, and asthma patients were excluded from the study. Patients who had MRI examination for control purposes and patients with nonspecific symptoms and no pathology were included in the study. The cases had nonspecific complaints such as headache and dizziness in order of frequency. No disease was detected in these paediatric individuals and no disease developed during clinical follow-up in our hospital.

In this study, 190 paediatric individuals who underwent cranial MRI between 2017 and 2019 were evaluated retrospectively. Cases with good image resolution and no motion artefact were included in the study, while cases with poor image resolution and artefacts were excluded. Ninety-five of our cases were females and 95 were males. Healthy paediatric cases were divided into four groups according to their age and gender: group 1: infantile period (1-24 months), group 2: early childhood (2-6 years), group 3: childhood (7-12 years) and group 4: adolescence (13-18 years); group A consisting of 95 females; group B consisting of 95 males. The study was conducted on the basis of and in accordance with the Declaration of Helsinki. OBV and OSD measurements were made on T2-weighted brain MRIs in the coronal plane (Fig. 1) obtained on a 3 Tesla MR (Magnetom Skyra, Siemens, Germany) device. Our imaging parameters were $256 \times 256$ matrix and $22 \mathrm{~cm}$ field of view (FOV), repetition time (TR): $3500 \mathrm{~ms}$, echo time (TE): $75 \mathrm{ms,}$ excitation number (NEX): 2 , and a slice thickness of $4 \mathrm{~mm}$. OBV and OSD measurements were made by two experienced radiologists who had no knowledge of the cases.

Volumetric measurement of OBV was made using three-dimensional Slicer software (3D Slicer software ver. 4.2.2-1, http://www.slicer.org). The Slicer volumetric measurement programme is a free open source software package developed by Harvard University and approved for medical research. After dividing the olfactory bulbus into sections with appropriate threshold values in the coronal image, separate MR numbers were assigned to each image with the Slicer software. Region of interest was adjusted to not exceed the anatomical contours of the bulb. After each slice containing the relevant $O B$ sections was revealed, a 3D graphical model of the OB was creat- 


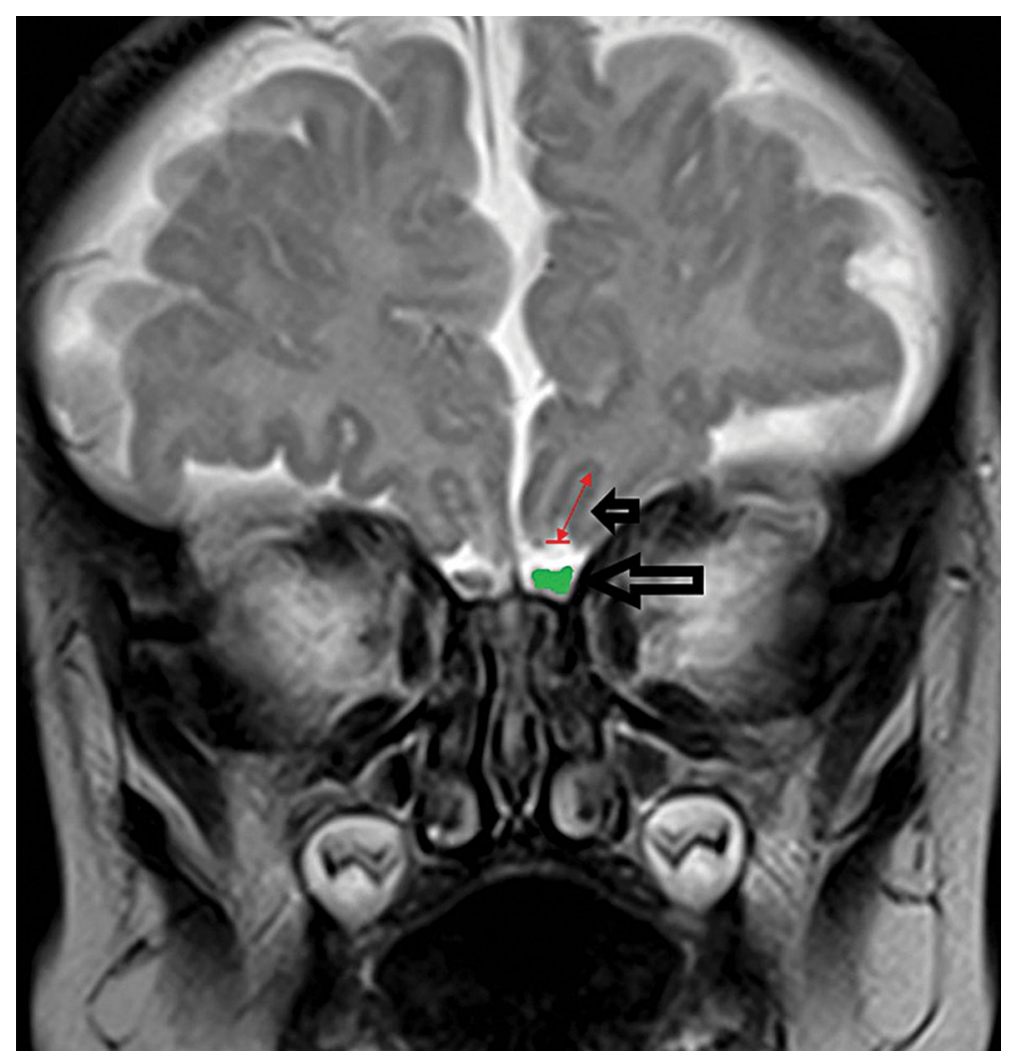

Figure 1. The coronal T2-weighted image shows the olfactory bulb volume measurement and the olfactory sulcus depth measurement. A measurement example of olfactory sulcus depth (small hollow arrow) and a measurement example of olfactory bulb surface area (large hollow arrow).

ed and volume calculation was made. Intra-observer variability was set at less than $5 \%$.

\section{Ethics Committee approval and consent to participate}

Ethics Committee aproval was given by Muğla Sıtkı Koçman University Human Research Ethics Committee. Ethics Committee Number: 200236.

Approval was obtained from the parent or legal guardian of each case participating in the study.

\section{Statistical analysis}

IBM SPSS version 20.0 software (IBM Corp, Armonk, NY, USA) was used for statistical evaluation and normal distribution was checked using Kolmogorov-Smirnov test. Data are presented as mean \pm standard deviation. Statistical comparisons of the right and left OBV values and the depth of the right and left olfactory sulcus were made using the paired $t$ test. Independent-sample $t$ test was used to evaluate the statistical differences between groups formed by considering gender, while one-way ANOVA test was used to evaluate the statistical differences between groups formed according to age. Multiple comparisons were made with the Tukey test and a $p$ value of 0.05 was considered statistically significant.

\section{RESULTS}

A total of 190 patients (95 males, 95 females) were included in the study. The mean age was $9.9 \pm$ \pm 7.5 months for the infantile period, $4.5 \pm 1.3$ years for early childhood, $9.3 \pm 1.7$ years for childhood and $15.2 \pm 1.7$ years for adolescence. The OBV was $42.03 \pm 5.96$ (range 29.2-57.6) $\mathrm{mm}^{3}$ on the right and $42.33 \pm 6.06$ (range $28.8-62.4$ ) $\mathrm{mm}^{3}$ on the left side. There was no statistical difference between right and left side OBV ( $p>0.167)$. Mean, right and left OBV was found to be slightly larger in male children than female children $(p=0.015, p=0.033$ and $p=0.010$, respectively) (Table 1 ). OSD values were $8.34 \pm 0.92 \mathrm{~mm}$ on the right and $8.32 \pm 0.89 \mathrm{~mm}$ on the left. There was no statistical difference between right and left in terms of OSD ( $p>0.481)$. There was no statistical difference between the genders 
Table 1. The distribution of age, mean, left and right olfactory bulb volume (OBV) and olfactory sulcus depth (OSD) according to sex

\begin{tabular}{cccc}
\hline & Group A ( $\mathbf{n}=95)$ & Group B $(\mathbf{n}=95)$ & $\mathbf{P}$ \\
\hline OBV $\left[\mathrm{mm}^{3}\right]:$ & & & \\
Mean & $41.15 \pm 5.32$ & $43.20 \pm 6.15$ & 0.015 \\
Right & $41.11 \pm 5.67$ & $42.95 \pm 6.14$ & 0.033 \\
Left & $41.20 \pm 5.35$ & $43.45 \pm 6.52$ & 0.010 \\
OSD [mm]: & & & \\
Mean & $8.37 \pm 0.92$ & $8.29 \pm 0.87$ & 0.559 \\
Right & $8.38 \pm 0.93$ & $8.30 \pm 0.92$ & 0.536 \\
Left & $8.36 \pm 0.93$ & $8.30 \pm 0.85$ & 0.598 \\
\hline
\end{tabular}

for mean, right and left OSD ( $p=0.559, p=0.536$ and $p=0.598$, respectively) (Table 1 ).

The distributions of mean OBV and OSD according to age groups are given in Table 2 . Among the age groups, the values of the $3^{\text {rd }}$ and $4^{\text {th }}$ groups in terms of mean, right and left OBV were higher than the other two groups $(p<0.001)$ (Table 2$)$. In terms of OSD, mean, right and left values were higher in group 2 , 3 and 4 than group $1(p<0.001)$ (Table 2 ).

\section{DISCUSSION}

There are several important results of our study. First, in the paediatric age group, the OBV increases as the age increases, but the most significant volume increase is in the 7-12 age group. Second, OSD is lower in the infantile patient group (1-24 months) compared to other paediatric age groups. After 3 years of age, there is no statistically significant change in the depth of the olfactory sulcus until the age of 18 . Third, there was no statistically significant difference in OSD measurements based on gender in the normal healthy paediatric population, but OBV was slightly larger in male children than in female children.

Magnetic resonance imaging method has been used successfully in adults to analyse the normal anatomy of $\mathrm{OBs}[4,6,12,20,23]$. In the study conducted by Schneider and Floemer [18], cranial MRI examinations of 121 paediatric cases aged between 1 and 19.6 years were retrospectively re-evaluated in order to detect the maturation of the $\mathrm{OB}$. Three anatomical patterns have been described defining different anatomical shapes for the olfactory bulbus. Whatever the anatomical shape of the OBs, they found that the gradual rearrangement of the peripheral neuronal layers and central structures of the bulbus resulted in an adult-like appearance in all children at the end of the second year at the latest, in parallel with the maturation changes of the cerebral white matter [18]. Therefore, in our study, we grouped paediatric individuals of the first 2 years of age separately. However, we found that OBV increased minimally in paediatric individuals aged 3-6 years compared to the first 2-year-old case group. We found the OSD to be lower in the first 2-year-old paediatric group compared to the other three paediatric groups. This finding supports this study by Schneider and Floemer [18] on olfactory maturation.

In a study conducted by Croy et al. [3] on 27 depressed female individuals, 15 of whom were maltreated during childhood, the OBV measured in individuals who were maltreated during childhood was found to be lower than those who were not exposed to child-

Table 2. The distribution of age, mean, left and right olfactory bulb volume (OBV) and olfactory sulcus depth (OSD) according to age group.

\begin{tabular}{|c|c|c|c|c|}
\hline & $0-2$ years $(n=40)$ & $3-6$ years $(n=50)$ & $7-12$ years $(n=50)$ & $13-18$ years $(n=50)$ \\
\hline Age [years] & $9.9 \pm 7.5$ & $4.5 \pm 1.3$ & $9.3 \pm 1.7$ & $15.2 \pm 1.7$ \\
\hline \multicolumn{5}{|l|}{$\mathrm{OBV}\left[\mathrm{mm}^{3}\right]$ : } \\
\hline Mean & $37.75 \pm 4.27$ & $39.26 \pm 5.95$ & $44.85 \pm 5.01^{a, b}$ & $44.96 \pm 5.72^{a, b}$ \\
\hline Right & $37.70 \pm 4.60$ & $39.08 \pm 5.98$ & $44.72 \pm 4.80^{\mathrm{a}, \mathrm{b}}$ & $44.88 \pm 6.07^{\mathrm{a}, \mathrm{b}}$ \\
\hline Left & $37.80 \pm 4.34$ & $39.44 \pm 6.31$ & $44.98 \pm 5.55^{\mathrm{a}, \mathrm{b}}$ & $45.03 \pm 5.81^{a, b}$ \\
\hline \multicolumn{5}{|l|}{ OSD [mm]: } \\
\hline Mean & $7.54 \pm 0.93$ & $8.56 \pm 0.78^{a}$ & $8.30 \pm 1.39^{a}$ & $8.60 \pm 0.78^{a}$ \\
\hline Right & $7.48 \pm 0.96$ & $8.58 \pm 0.78^{a}$ & $8.49 \pm 0.71^{\mathrm{a}}$ & $8.64 \pm 0.82^{\mathrm{a}}$ \\
\hline Left & $7.60 \pm 0.95$ & $8.53 \pm 0.81^{\mathrm{a}}$ & $8.45 \pm 0.74^{\mathrm{a}}$ & $8.56 \pm 0.77^{\mathrm{a}}$ \\
\hline
\end{tabular}

Data are $\mathrm{n}$ of participants, mean \pm standard deviation; ${ }^{a} \mathrm{p}<0.001$ compared with $0-2$ years group (one-way ANOVA-Tukey test); ${ }^{b} p<0.001$ compared with $3-6$ years group(one-way ANOVA-Tukey test) 
Table 3. Comparison of olfactory bulb volume (OBV) and olfactory sulcus depth (OSD) studies in healthy paediatric cases

\begin{tabular}{|c|c|c|c|c|c|c|c|c|}
\hline First author & Year & Country & Measurement method & $\mathbf{N}$ & Age & Magnetic field & $\mathrm{OBV}\left[\mathrm{mm}^{3}\right]$ & OSD [mm] \\
\hline \multirow[t]{2}{*}{ Hummel T. } & \multirow[t]{2}{*}{2011} & \multirow[t]{2}{*}{ France } & \multirow{2}{*}{$\begin{array}{l}\text { AMIRA 3-D visualisation } \\
\text { and modelling system } \\
\text { (Visage Imaging, } \\
\text { Carlsbad, USA) }\end{array}$} & \multirow[t]{2}{*}{87} & \multirow[t]{2}{*}{$1-17$ years } & \multirow[t]{2}{*}{1.5 Tesla } & $\begin{array}{c}\text { M: 21-98 } \\
\text { R: 68; L: } 71\end{array}$ & \multirow[t]{2}{*}{ No measurement } \\
\hline & & & & & & & $\begin{array}{l}\text { F: } 21-121 \\
\text { R: } 66 ; \mathrm{L}: 65\end{array}$ & \\
\hline \multirow[t]{2}{*}{ Sahin S. } & \multirow[t]{2}{*}{2020} & \multirow[t]{2}{*}{ Turkey } & \multirow{2}{*}{$\begin{array}{l}\text { Semi-automatically } \\
\text { method, Philips } \\
\text { workstation }\end{array}$} & \multirow[t]{2}{*}{90} & \multirow[t]{2}{*}{$3-17$ years } & \multirow[t]{2}{*}{1.5 Tesla } & $\begin{array}{l}\text { M: } 32.7-98.6 \\
\text { R: } 64 ; \text { L: } 65.3\end{array}$ & $\begin{array}{l}\mathrm{R}: 8.85(\min 6 \\
\quad \max 13.6)\end{array}$ \\
\hline & & & & & & & $\begin{array}{l}\text { F: } 31.8-99.6 \\
\text { R: 67.1; L: } 72\end{array}$ & $\begin{array}{l}\mathrm{L}: 8.8(\min 1.8 \\
\quad \max 16)\end{array}$ \\
\hline \multirow[t]{2}{*}{ Our study } & \multirow[t]{2}{*}{2020} & \multirow[t]{2}{*}{ Turkey } & \multirow{2}{*}{$\begin{array}{l}\text { 3D Slicer software } \\
\text { (3D Slicer software } \\
\text { ver. 4.2.2-1, USA) }\end{array}$} & \multirow[t]{2}{*}{190} & \multirow[t]{2}{*}{$\begin{array}{l}1 \text { month- } \\
-17 \text { years }\end{array}$} & \multirow[t]{2}{*}{3 Tesla } & $\begin{array}{c}\text { M: } 30.1-62.4 \\
\text { R: 41.11; L: } 41.20\end{array}$ & \multirow[t]{2}{*}{$\begin{array}{l}R: 8.34 \pm 0.92 \\
L: 8.32 \pm 0.89\end{array}$} \\
\hline & & & & & & & $\begin{array}{c}\text { F: } 29.2-55.2 \\
\text { R: } 42.95 ; \mathrm{L}: 43.45\end{array}$ & \\
\hline
\end{tabular}

F - females; $M$ - males; L - left; $R$ - right

hood maltreatment [3]. In the first hypothesis they put forward for this result they suggests that major stress exposure in childhood affects neurogenesis in human $\mathrm{OB}$, as previously demonstrated in animal studies [7]. For these reasons, we think that, as in our study, it is important to know the normal OBV and OSD measurement intervals in paediatric individuals to determine the connection between the abnormalities that may occur in adulthood and the paediatric period.

In a study conducted by Hummel et al. [9] on 87 paediatric individuals aged between 1 and 17 years without olfactory dysfunction (mean: $8 \pm 5.5$ years, 46 boys and 41 girls), it was found that OBV and olfactory function increased with age. In this study, OBVs of male children (left: $71 \mathrm{~mm}^{3}$, right: $68 \mathrm{~mm}^{3}$ ) were found to be larger than female children (left: $65 \mathrm{~mm}^{3}$, right: $66 \mathrm{~mm}^{3}$ ). It was also found that for both boys and girls, the right and left OBVs gradually increased from the age of 1 year. According to the study, the mean OBV for 1 year old boys is: left: 65 , right: $64 \mathrm{~mm}^{3}$; mean OBV for girls: left: 61 , right: $62 \mathrm{~mm}^{3}$. When the mean OBV was evaluated in 17-year-old paediatric individuals, in boys: left: $79 \mathrm{~mm}^{3}$, right: $77 \mathrm{~mm}^{3}$; in girls: left: $73 \mathrm{~mm}^{3}$, right: $71 \mathrm{~mm}^{3}$. As a result of our study, OBV was found to be slightly higher in boys compared to girls, similar to the study of Hummel et al. [9]. However, although OBV increased gradually with age, it was found that the statistically more significant increase in OBV was between the ages of 7-12, regardless of gender.

In studies conducted in patients with congenital anosmia and psychiatric disorders such as schizophrenia or psychosis, OSD was found to be lower than normal [9, 14, 21, 22]. Although standard values for the depth of the olfactory sulcus have been published mostly for adults, few studies have published standard values for the paediatric age group. In the study conducted by Smitka and Hummel [19] on 40 normosmic children aged between 6 and 18 years, it was found that OSD was $8 \mathrm{~mm}$ and above in all children over 9 years old. It was stated that the recommended cut-off value of $8 \mathrm{~mm}$, which indicates anosmia, can be used safely for children aged 9 years and older, and different limit values should be considered for children aged 8 years and younger. In the study conducted by Huart et al. [8] in 106 individuals (36 anosmic individuals and 70 healthy individuals) aged between 7 and 79 years, sulcus depth below $8 \mathrm{~mm}$ was found to be an important indicator for the development of anosmia [8].

The first study in the literature examining the age-related change of both OSD and OBV in healthy paediatric individuals was conducted by Şahin et al. [16]. A total of 90 paediatric patients aged between 3 and 17 years were included in this study and a 1.5 Tesla MRI device was used [16]. Our study is fundamentally different from 3 aspects according to the study of Şahin et al. [16]. The first is that healthy paediatric individuals in the 1 month- 2 years age group were included in the study and the study was conducted with 190 individuals, the second is the use of 3 Tesla MRI device and the third is that the OBV measurement method was different. Thus, the change in OBV and OSD in all paediatric age groups between 1 month and 17 years was examined. Studies including OSD and OBV measurements of healthy paediatric individuals in the literature are summarised comparatively in Table 3. 
According to our research, our study is the first study to separately show the development and change of the olfactory sulcus depth for four separate periods after birth until the age of 18 in healthy paediatric individuals. It was found that OSD gradually increased with age in both healthy male and female individuals in the paediatric age group. The infantile group (0-24 months) had the lowest OSD and the mean OSD in this group was found to be less than $8 \mathrm{~mm}$. For patients aged 3 years and older, mean OSD was over $8 \mathrm{~mm}$ for each age group. Another difference between our study and other studies is that the images were obtained with a 3 Tesla MR scanner. We think that we may have obtained more accurate results since 3 T MRI provide clearer and thinner-slice images with higher resolution.

\section{Limitations of the study}

Our study had some limitations. The first of these is that our study was retrospective and there was no evaluation of olfactory function. In addition, inter-observer variability was not taken into account in our study. Another limitation is that some of the individuals participating in the study were very young and the patient backgrounds were obtained from the hospital information system.

\section{CONCLUSIONS}

In conclusion, there are still very few studies showing the development of OBV and OSD with age and time changes considering gender for normal healthy paediatric individuals. We think that more studies should be done on this subject, since these data show differences in both the paediatric age group and adults according to age and that OBV and OSD can be an indicator of the development of olfactory dysfunction. Therefore, within the paediatric age group, normal values should be calculated considering age and gender.

\section{Conflict of interest: None declared}

\section{REFERENCES}

1. Asal N, Bayar Muluk N, Inal M, et al. Olfactory bulbus volume and olfactory sulcus depth in psychotic patients and patients with anxiety disorder/depression. Eur Arch Otorhinolaryngol. 2018; 275(12): 3017-3024, doi: 10.1007/ s00405-018-5187-x, indexed in Pubmed: 30382395.

2. Azoulay R, Fallet-Bianco C, Garel C, et al. MRI of the olfactory bulbs and sulci in human fetuses. Pediatr Radiol. 2006; 36(2): 97-107, doi: 10.1007/s00247-005-0030-0, indexed in Pubmed: 16341529.
3. Croy I, Negoias S, Symmank A, et al. Reduced olfactory bulb volume in adults with a history of childhood maltreatment. Chem Senses. 2013; 38(8): 679-684, doi: 10.1093/ chemse/bjt037, indexed in Pubmed: 24051351.

4. Çullu N, Yeniçeri iÖ, Güney B, et al. Evaluation of olfactory bulbus volume and olfactory sulcus depth by $3 \mathrm{~T}$ MR. Surg Radiol Anat. 2020; 42(9): 1113-1118, doi: 10.1007/ s00276-020-02484-w, indexed in Pubmed: 32377954.

5. Doğan A, Bayar Muluk N, Asal N, et al. Olfactory bulb volume and olfactory sulcus depth in patients with Behçet's disease. J Laryngol Otol. 2018; 132(12): 1088-1092, doi: 10.1017/S0022215118002141, indexed in Pubmed: 30558688 .

6. Held P, Seitz J, Fründ R, et al. MRI detection of olfactory bulb and tract. J Neuroradiol. 2000; 27(2): 112-118.

7. Hitoshi S, Maruta N, Higashi M, et al. Antidepressant drugs reverse the loss of adult neural stem cells following chronic stress. J Neurosci Res. 2007; 85(16): 3574-3585, doi: 10.1002/jnr.21455, indexed in Pubmed: 17668856.

8. Huart C, Meusel T, Gerber J, et al. The depth of the olfactory sulcus is an indicator of congenital anosmia. Am J Neuroradiol. 2011; 32(10): 1911-1914.

9. Hummel T, Damm M, Vent J, et al. Depth of olfactory sulcus and olfactory function. Brain Res. 2003; 975(1-2): 85-89, doi: 10.1016/s0006-8993(03)02589-7, indexed in Pubmed: 12763595.

10. Hummel T, Smitka M, Puschmann S, et al. Correlation between olfactory bulb volume and olfactory function in children and adolescents. Exp Brain Res. 2011; 214(2): 285-291, doi: 10.1007/s00221-011-2832-7, indexed in Pubmed: 21842188.

11. Hummel T, Urbig A, Huart C, et al. Volume of olfactory bulb and depth of olfactory sulcus in 378 consecutive patients with olfactory loss. J Neurol. 2015; 262(4): 1046-1051, doi: 10.1007/s00415-015-7691-x, indexed in Pubmed: 25712545.

12. lida $Y$, Naito $M$, Asahina $N$, et al. Magnetic resonance imaging of the olfactory apparatus. Arch Otolaryngol Head Neck Surg. 1994; 120(8): 869-872, doi: 10.1001/archotol.1994.01880320069015, indexed in Pubmed: 8049051.

13. Müller F, O'Rahilly R. Olfactory structures in staged human embryos. Cells Tissues Organs. 2004; 178(2): 93-116, doi: 10.1159/000081720, indexed in Pubmed: 15604533.

14. Nishikawa Y, Takahashi T, Takayanagi Y, et al. Orbitofrontal sulcogyral pattern and olfactory sulcus depth in the schizophrenia spectrum. Eur Arch Psychiatry Clin Neurosci. 2016; 266(1): 15-23, doi: 10.1007/s00406-015-0587-z, indexed in Pubmed: 25757375.

15. O'Rahilly R, Müller F, Bossy J, et al. [Atlas of the stages of development of the nervous system in the intact human embryo]. Arch Anat Histol Embryol. 1982; 65: 57-76, indexed in Pubmed: 6764349.

16. Sahin S, Baykan AH, Altunisik E, et al. Quantitative analysis of healthy olfactory sulcus depth, olfactory tract length and olfactory bulb volume in the paediatric population: a magnetic resonance study. Folia Morphol. 2021; 80(1): 33-39, doi: 10.5603/FM.a2020.0125, indexed in Pubmed: 33084007.

17. Sarnat HB, Flores-Sarnat L. Olfactory development, part 2: neuroanatomic maturation and dysgeneses. J Child Neurol. 2017; 32(6): 579-593, doi: 10.1177/0883073816685192, indexed in Pubmed: 28424008. 
18. Schneider JF, Floemer F. Maturation of the olfactory bulbs: MR imaging findings. AJNR Am J Neuroradiol. 2009; 30(6): 1149-1152, doi: 10.3174/ajnr.A1501, indexed in Pubmed: 19279285.

19. Smitka M, Hummel T. The depth of the olfactory sulcus in normosmic children and adolescents. Neuropediatrics. 2015; 46(S 01): WS07-1, doi: 10.1055/s-0035-1550753.

20. Suzuki M, Takashima T, Kadoya M, et al. MR imaging of olfactory bulbs and tracts. AJNR Am J Neuroradiol. 1989; 10(5): 955-957, indexed in Pubmed: 2505540.

21. Takahashi T, Nakamura Y, Nakamura K, et al. Altered depth of the olfactory sulcus in first-episode schizophrenia.
Prog Neuropsychopharmacol Biol Psychiatry. 2013; 40: 167-172, doi: 10.1016/j.pnpbp.2012.10.001, indexed in Pubmed: 23063493.

22. Turetsky BI, Moberg PJ, Quarmley M, et al. Structural anomalies of the peripheral olfactory system in psychosis high-risk subjects. Schizophr Res. 2018; 195: 197-205, doi: 10.1016/j. schres.2017.09.015, indexed in Pubmed: 28974405.

23. Yousem DM, Geckle RJ, Bilker WB, et al. Olfactory bulb and tract and temporal lobe volumes. Normative data across decades. Ann N Y Acad Sci. 1998; 855: 546-555, doi: 10.1111/j.1749-6632.1998.tb10624.x, indexed in Pubmed: 9929650. 